\title{
Research on Venture Service System of Resource-Exhausted Cities
}

\author{
Huiping Fen and Min Zeng
}

Pingxiang University, Pingxiang, Jiangxi, China, 337055

\section{Keywords: Venture, Service System, Resource-Exhausted Cities}

\begin{abstract}
With the natural resources are of the brink of exhaustion, resource-exhausted cities facing economic growth stagnated, employment pressure surge, shortage of financial resources, living difficulties, the ecological damage to the environment and other issues at varying degrees. Among them, the fundamental problem is employment which is tied to social stability and as a constraint to urban economic transformation, social development and political stability bottlenecks.
\end{abstract}

\section{Introduction}

With the natural resources on which the survival and development of the brink of exhaustion, resource-exhausted cities facing varying degrees of economic growth stagnated, employment pressure surge, shortage of financial resources, living difficulties, the ecological damage to the environment and other issues. Among them, the fundamental problem of employment livelihood, tied to social stability, as a constraint to urban transformation, social development bottlenecks. Therefore, how to guide the transformation of resource-exhausted cities urban development model, it renewed vigor and vitality, how to actively support the masses resource-exhausted cities to get rid of the plight of survival, sustainable development coordinator with the natural environment, it is placed in public before the Chinese government.

At the same time, employment policy agenda of resource-exhausted cities in transition cannot ignore the demands of the times. Carbon activity due to extensive use of fossil energy generated caused by global climate change has become a major hidden threat to human survival and development, the development of low-carbon economy has become a trend of world economic development. As a developing country is in a period of rapid industrialization development, on which the long-term China's coal-dominated energy structure of high-carbon development, increasing energy consumption and the deterioration of the ecological environment. Sharp increase in domestic energy consumption, the international face of enormous pressure to reduce emissions, the objective is to show that a low carbon economy has become a challenge to the Chinese government to deal with energy shortages, environment and climate change, mitigation of economic growth, employment, energy conservation, etc. multiple target pressure of the inevitable strategic choice.

Under the new era background, the macro-development path of low-carbon economy, to a resource-exhausted cities in transition and employment policy has brought new development ideas, but also for local governments poses a severe challenge: how to break complex storm Bureau, under the guidance of the central government in a timely manner to adjust their roles, through careful and systematic policy arrangements to co-ordinate environmental governance and economic transformation coordinated development, and guide the industrial structure and beneficial interaction between resource-exhausted cities of employment structure, and then realize positive impact on employment, placed in front of the government's major task, but also become the focus of recent theoretical research.

\section{The Concept of Resource-Exhausted Cities}

Resource-exhausted cities, literally refers to the exploitation of resources going to finish or has no available resources, a city often referred to as resource-exhausted cities. It is a process, a non-static concept. For Fuxin City, just exhausted coal mines, where coal accounts for a large portion of the main body of Fuxin resources for other industries also has mining properties. For example, in 2012, 
for the first time in Fuxin proven shale gas resources, it is expected to exceed 8.7 billion cubic meters the amount of resources, enough for 24 million homes for one year. Shale gas belongs to the owned natural gas resources, the main component is methane, with a long mine life, long production cycle, with environmental protection, etc., it is China's first 172 independent minerals.

Different scholars define resource-exhausted cities have a different understanding, now still have differences, but also made some fruitful results. Zhang Pei pro, Sun Yue said: refers to resource-exhausted cities in history due to natural resources, energy and mineral resources rise, is now in a state of natural resources depletion and even dropped, but did not achieve the transformation of the city. Academic resource-exhausted cities usually see two categories, from an academic point of view, resource-exhausted cities refer to "rely on the construction of its main resource development or extraction into the late stage, resource recovery has proven recoverable reserves accounted for $70 \%$ or more, mining design life time accounts for more than three quarters of the resource-based cities. "In theory, energy and mineral resources are non-renewable resources, will one day be depleted because of over-exploitation, called resource-exhausted cities. To sum up, I think, resource-exhausted cities means that when the city relies on natural resources, and cannot be reversed when the energy industry is about to collapse, called the resource-exhausted cities. Our resource-exhausted cities have 118, mainly in the eastern regions. Such as: the middle of Inner Mongolia, Shanxi and other eastern Heilongjiang, Jilin, Hebei and so on.

\section{The Unemployment Situation of Resource-Exhausted Cities}

According to the fifth census data show that China's urban labor force participation rate was 67.7\%, the unemployment rate was $8.21 \%$; the labor force participation rate of non-resource-based cities of $68.16 \%$, the unemployment rate was $7.87 \%$; resource-exhausted cities labor force participation rate only 63.54 percent, the unemployment rate was as high as $12.3 \%$, the level of unemployment was significantly higher than non-resource-based cities.

From the source of the unemployed, laid-off workers is the direct source of urban ranks of the unemployed, and the laid-off workers are mainly concentrated in the state-owned enterprise. Resource-exhausted cities is the state-owned enterprises are relatively concentrated areas, thus becoming the laid-off, unemployed most serious. Laid off from state-owned enterprises is the largest area of Liaoning Province, laid-off workers in 1998 amounted to 58.9 million, followed by Heilongjiang, 52.8 million people, 34 million people in Jilin; workers laid off from state-owned enterprises in Northeast China accounted for a quarter of the national total. Fuxin City in 2002, the city laid-off and unemployed persons amounted to 15.6 million, ranking first in the country, urban residents below the Poverty Line 17.8 million. In addition, due to lack of unemployment statistics, the real unemployment rate is high. 1997 Tangshan registered urban unemployment rate was $2.48 \%$, well below the national average of $3.1 \%$, but then did not participate in the registration of 7.1 million laid-off workers, two together, the real unemployment rate was 9.44\%, far higher than the national the unemployment rate $(6.7 \%)$ of the average.

The unemployed concentrated in the extractive industries and the knowledge and skills structure is irrational. Mineral resources mining industry is a labor-intensive industries, the proportion of resource-based cities a considerable part of the population are employed in the extractive industries. In 1990, the number of resource-based cities in the extractive industries was 472.05 million, accounting for all workers in the industry workers accounted for $18.59 \%$; the number of non-resource-extractive industries in the cities of 589.16 million, accounting for all the workers in this industry work who accounted for 3.49\%. In 2000, the number of resource-based cities in the extractive industries was 290.85 million, the proportion of workers in the industry was 10.39 percent of all workers, compared to 1990 the number of resource-based cities in the extractive industry decreased 181.

Structural unemployment is a prominent characteristic of resource-exhausted cities unemployment. Structural unemployment refers to unemployment economic structural changes and other causes, which is characterized by both unemployed, there are vacancies.

Resource-exhausted cities have entered a recession after the implementation of economic 
transition, the focus of economic development gradually shift from the traditional resource-based industries in the direction of processing and manufacturing, high-tech industries, modern service industry and other logistics, the quality of the labor force has also put forward a new Claim. Resource-exhausted cities, long relied on low-tech, labor-intensive traditional industries and the expansion of economies of scale, compared to non-resource-based cities, gathered a large number of low quality of the workforce, the primary vocational skills and relative surplus labor, with senior professional skills of the labor force relative shortage, making it impossible to meet the needs of the labor market, leading to unemployment and more resource-exhausted cities to structural unemployment.

Hidden unemployment also known as potential job or unemployed referring to the workers employed by the employer cannot be fully engaged in the work of its ability to engage in the kind of labor productivity or lower than he could reach the standard of work. Its typical feature is the employment of workers in name, but in fact in a state of unemployed or underemployed. Due to the planned economy period "widespread employment" that guide thoughts, in which state-owned and collective enterprises, government agencies and institutions of various types to form a large number of hidden unemployed. This part of the existence of hidden unemployed persons can easily result in labor inefficiency, indiscipline, waste of human resources and so on, seriously affected the economy sustained rapid healthy and coordinated development.

\section{Cause Analysis of Unemployment in Resource-Exhausted Cities}

Since the reform and opening up, China's economic system from a planned economy to a market economy, the country unified deployment of resources from the original steering according to laws of the market self-regulation. China's resource-based cities are mostly built under the planned economic system and the economic system of resource-exhausted cities Unemployment in China has had a profound impact.

Under the planned economy system, the government in the configuration of all resources on the basis of macro-allocation of labor resources, through the intervention of businesses and employers, artificially placed a large number of workers in state-owned enterprises to achieve macro-balance high employment rate and labor on the surface. Allocation of labor resources under the planned economy, although the ease employment pressure on society, but much higher than the state-owned enterprises own human effective demand, so that the enterprise has accumulated a large number of surplus personnel, the formation of hidden unemployment.

By the market allocation of all resources, including labor, the Government merely through labor market interventions, efforts to control the unemployment rate remained at the level of the natural rate of unemployment. Balanced labor market economy is no longer based on a fair and first, in order to become the first efficiency. With the economic system, the role of the market mechanism occurs efficiency of input-output behavior of state-owned enterprises. The face of market pressures by state-owned enterprises began to change in labor input to enhance the competitiveness of their products. Configuration to labor market, the government is no longer able to businesses mandatory allocation of labor. Thus, the original hidden unemployment is becoming dominance of state-owned enterprises.

The second industry has become the main industry of urban development, primary industry and tertiary industry development is weak, urban functions weakened. The first major industry is extensive management of traditional agriculture, secondary industry are mostly for the resource-based enterprise services business and catering industry, the second industry, mostly extractive industries and supporting industries as the leading industrial chain is very short. Economic development of the city is highly dependent on resources, industry association of the city is at the end of each horizontal coordinate industrial poor, low level of vertical, industrial transformation of weak foundation.

Public reemployment service development lags behind. Resource-exhausted cities low level of public re-employment service is an important cause of their unemployment. From the beginning of the 1980s, set up and improved content including outplacement, employment training, 
unemployment insurance and employment service enterprises and other employment service system. Due to rapid economic restructuring system, the deepening of the reform of state-owned enterprises, in a planned economy to a market economy in the process, the rapid release of large numbers of workers to the labor market, the existing employment service system cannot meet the needs of urban employment.

\section{Policy to Promote Employment in Resource-Exhausted Cities}

China's large population, a huge amount of labor resources, in the full realization of industrialization and urbanization of the whole process, full employment will become all levels of government must seriously confront and properly solve difficult problems. Employment is the Thing, also related to reform, development and stability. It is not only an economic issue, but a social problem, a political problem. To this end the Government at all levels must resolutely implement the principle of giving priority to employment.

Because our country had long planned economy system, under the planned economic system, resource-exhausted city workers have for the country to create a precious value, made a great contribution. The main reason for the mineral resources in these cities tends to dry, which was mainly to meet the needs of national development industry, especially heavy industry. China has now established the basis of socialist industrialization, however, a large number of jobs in the city has been the main minerals industry workers because of depletion of resources and have lost their old jobs, this is not their personal cause, but they are subject to State results overall interests formed. So the government solve the employment difficulties of resource-exhausted cities laid-off workers, the problem is the bounden duty of the government should give full play to its leading role in identifying and implementing the correct principles and policies, power to mobilize all aspects of active and steadily solve the laid-off workers re Employment issues.

Develop broader development plans. At the insistence of the basic law of the market economy under the premise of scientific development to guide the overall development planning of resource-exhausted cities and specifically planning for the promotion of employment. Through macro guidance of state, the resource-exhausted cities to facilitate appropriate employment inclined to create a favorable policy environment for resource-exhausted cities to promote employment.

\section{Conclusion}

Resource-exhausted cities unemployment is a more complex theoretical and practical issues involved in a lot of content, to conduct a comprehensive and thorough research is a difficult job. Because of inherent limitations in the labor market, relying solely on the automatic adjustment mechanisms cannot achieve the goal of full employment, and the right to employment substantially reflect the basic rights to survival and development of citizens, which has a "public good" of the property, so the government It plays a crucial role in the promotion of employment, and must undertake to fulfill the obligations as positive.

\section{Acknowledgements}

Fund Project: A New Round of Education Examination Enrollment System Reform Research Projects (1523).

\section{References}

[1] Fanjun Fu, Baixu Jun, Sun Bin. The resource-exhausted cities with economies in transition and the coordinated development of ecological security [J] Energy and Environment, 2005, 01: 22-24

[2] Fang Weicheng. government to play an active role in promoting low-carbon economy [J] renewable resources, 2009, 11: 44-45 
[3] Gu Jie. Research on resource-based Urban Economic Transition Government Transformation: In the first batch of pilot cities for resources cities Daye City as an example [J] Wuhan University of Science and Technology (Social Science Edition), 2009,11 (3): 1-4.

[4] Hu Xueqin. Foreign Unemployment Survey on the Types[J]. Economic Survey, 2001, 04: 41-43.

[5] Hou Min, Liuzhao Li. The resource-exhausted cities Industry Selection - A case study of the Fushun example [J] Resources • Industry, 2006, 01: 4-8. 